\title{
Postural assessment, Part Two: Deviation for sense of, and actual alignment
}

\author{
Petronella Hough, B. OccTher (UFS); M Occ Ther (UFS) http://orcid.org/0000-000 I-993 I-6360 \\ Lecturer, Department of Occupational Therapy, University of the Free State
}

Mariette Nel, BA (UFS), BA Hons (UFS), M Med Sc in Biostatistics (UFS) http://orcid.org/0000-0002-3889-0438

Lecturer, Department of Biostatistics, University of the Free State

Introduction: Accurate sensing of the body position in space is important for safe and mechanically effective interaction with the environment. Clinical evidence however suggests that a client's sense of postural alignment differs from their actual alignment, which may influence the accuracy of postural repositioning during participation in activities of daily life.

Objectives: The aim of this quantitative descriptive study was to investigate the difference between sense and actual postural alignment during sitting and standing positions, with the anatomical landmarks as reference points for measurement from anterior and lateral views.

Methods: Ten health care clinics in the Free State towns of Botshabelo and Thaba N'chu, were randomly selected and 95 patients participated in the study. Measurements consisted of (a) a biographical questionnaire, (b) assessment of actual postural alignment, and (c) assessment of sensed postural alignment. Assessment of actual postural alignment was done by using the Photographic Method of Postural Assessment (P-MPA), during which the actual (real) distance on photos was established by calculating the ratio of measured/ real distance $x$ distance from plumb line for each photo. A clinical significant difference from the reference point as measured on the photo was set at $10 \mathrm{~mm}$. The sense and actual deviation, for sitting and standing were compared by means of $95 \%$ confidence intervals for median differences.

Results: Results show statistical and clinically significant differences for sense and actual deviations from the plumb line for lateral views for all anatomical landmarks, in both sitting and standing positions. With the exception of a clinical significant difference at the nose landmark in anterior view, results show no other statistical or clinical significant differences for anterior sitting or standing.

Recommendations: The authors recommend that follow up studies investigate postural repositioning during motion and in addition to speed and direction, also test the degree to which discrepancy between sense and actual values occurs.

Conclusion: Increased awareness by health care professionals and educators of the discrepancy between sensed and actual postural alignment, in anterior and lateral views, may benefit the planning of intervention programmes aimed to enhance safe and meaningful occupational performance.

Key words: Postural alignment, sense of posture and actual posture

\section{INTRODUCTION AND LITERATURE REVIEW}

Health care practitioners treat clients with postural deviations by following (among others) an educational approach ${ }^{1,2,3}$ to correct postural alignment in order to perform safe ${ }^{4,5}$, precise and accurate movement during activities of daily life ${ }^{6}$, and to enable mechanically effective movement ${ }^{7}$. The Posture Committee of the American Academy of Orthopaedic Surgeons ${ }^{8: 1}$, defines posture as "the relative arrangement of the parts of the body", and state that normal posture refers to muscular and skeletal balance which protects the supporting structures of the body against injury or progressive deformity irrespective of the working of resting positions of these structures. Kendall ${ }^{9}$ regards postural alignment as ideal when specified anatomical landmarks align with a plumb line, representing a vertical line of gravity through the centre of gravity. This functions as the single point around which the mass of the body is equally distributed $^{10}$.

Sensing the body's location in external space is important for interacting with the environment ${ }^{11}$. Research findings on the accuracy of sensing postural alignment in literature are mainly focussed on the sense of single joint positions and the influence of external factors on joint positions ${ }^{12,13}$, as well as matching sensed posture of opposite joints ${ }^{14,15}$. Most studies on the accuracy of sensed posture have been performed at the knee joint ${ }^{16-20}$. Results from a study ${ }^{16}$ that investigated the difference of sensed posture using open kinetic chain and closed kinetic chain (CKC) found a mean error of $5,5^{\circ}$ and concluded that the mean error in sensed posture is less in CKC. Cheuh-Ho Lin et al..$^{21}$ proved an insignificant mean error of $0.6^{\circ}$ for sensed posture in healthy ankles. Olson, et al. ${ }^{15}$ found that contralateral assessment showed a greater mean error than ipsilateral assessment. Brindle et al. ${ }^{22}$ states that visual feedback enhances sensed posture, while Gibson ${ }^{23}$ proved vision to be more dominant than touch and proprioception. Far less research evidence is available on sense of position of the shoulder and elbow joints. Correlation between sensed posture position and sensed posture error $^{12}$ between shoulder and elbow joint indicates similar errors in sensed posture and further indicate that sensed posture error decreases nearing end-range of motion. King, Harding and Karduna ${ }^{14}$ further found no significant differences in sensed posture between left and right upper extremity joints, and proved that the mean error for the shoulder joint was greater than the elbow joint.

Unpublished research findings ${ }^{24}$ indicate that whole body posture (multi-joint), sense of posture is more accurate in anterior planes than in the lateral planes, and that the number of participants with actual deviation in posture is more than the number of participants who sensed a deviation in their postural alignment. 
This finding implies that participants who actually deviate from the plumb line in their postural alignment, often do not know the extent to which they deviate.

During clinical intervention it is implicitly assumed that a client is able to accurately perceive and interpret their own postural alignment $^{25}$ in relation to ideal alignment, and that posture behaviour adjusts accordingly ${ }^{26-29}$ during the performance of activities of daily life. The researchers of the current study argue that postural intervention may be more efficient if the differences between sensed and actual posture is known, and that the differences are considered in occupational assessment and intervention programmes. Attempts to improve on current postural intervention strategies should therefore note possible differences between sensed and actual postural alignment, in order to optimise intervention with combined modalities of education and proprioceptive intervention strategies.

In the absence of published research evidence that report on the sense of postural alignment on a multi-joint level ${ }^{30,31}$, as they compare to actual alignment, this study aimed to investigate the difference between sense of postural alignment and the actual postural alignment in sitting and standing, from both anterior and lateral views, for specified anatomical landmarks.

\section{METHODOLOGY}

\section{Study Design}

A quantitative cross-sectional descriptive design was selected to perform this study. Ethical clearance was obtained from the Health Sciences Research Ethics Committee at the University of the Free State (HSREC I7I/20I6/I4I5). Permission to conduct the study was obtained from the District Manager, Mangaung Metro and the Free State Provincial Health Research Committee.

\section{Sampling}

Of the 26 public health care clinics in Botshabelo and Thaba N'chu, ten clinics were randomly selected and a convenient sample of 10 patients per clinic participated in the study if they met the specified inclusion criteria. Patients were included if they were able to assume a standing and sitting position for 2 minutes, willing to participate in the study, and able to speak English, Afrikaans or Sesotho. Patients were excluded if they reported hearing impairments or a spinal cord trapped nerve, or if they were diagnosed with acute muscu- loskeletal injury and/or musculoskeletal pathology such as cerebral palsy, scoliosis or radiculopathy.

\section{Data collection}

Prior to the day of data collection, each clinic was visited by a trained fieldworker (qualified occupational therapist) who informed the clinic personnel about the procedure for data collection, where after a suitable venue was located at each respective clinic for this purpose. On the day of data collection all patients who attended the clinic were informed about the study, and signed informed consent was obtained to participate in the study. The field worker provided the participant with information regarding the procedure of postural assessment.

Measurement comprised three parts namely: a biographical questionnaire, measurement of actual postural alignment and sensed postural alignment. Actual- and sensed postural alignment were assessed using the Photographic Method of Postural Assessment (P-MPA) ${ }^{32}$.

Data collection phase: To assess postural alignment, a set-up for postural assessment was done according to the P-MPA procedure (Figure I below). A number for each individual participant, as well as a I meter ruler to indicate actual distance (as per the P-MPA ${ }^{32}$ ratio measurement) were pasted on the wall in front of which the participant was placed.

\section{Method}

\section{Assessment: marking of anatomical landmarks}

The participant was requested to assume a comfortable standing position, for the marking of the following landmarks by making use of a $5 \mathrm{~mm}$ reflective sticker:

* lateral view: anterior aspect of lateral malleolus, mid-knee, greater trochanter, acromion and external auditory meatus (ear lobe);

* anterior view: mid-heels, mid-knees, navel and nose.

\section{Assessment of posture}

The participant assumed a position I meter behind the plumb line, with the plumb line aligned with the anterior aspect of the lateral malleoli for the standing position, and with the plumb line aligned with mid heels for the anterior position. The participant was asked to assume his/her most natural standing and sitting position. For the taking of measurements, the field worker assumed a position 2 metres from the plumb line. A photo was taken by the field worker using a smartphone that was fixed on a tripod at a height of $950 \mathrm{~mm}$. After the photo had been taken the participant's sense of posture was assessed by asking the participant to indicate their sensed deviation from the plumb line on a ruler for all the anatomical landmarks (Figure 2 page 40). Measurements were then documented on the data form (Figure 2) for sitting and standing in both lateral and anterior views. At the end of each day each photograph was printed in A4 size, after which each participant's actual deviations from the plumb line were measured with a ruler with increments in millimetres, and transferred to data forms.

The actual (real) distance on photos was established by calculating the ratio of measured/real distance $x$ distance from plumb line for each photo ${ }^{32}$. A clinical significant difference from the reference point as measured on the photo was set at $10 \mathrm{~mm}^{33}$. The coding was done by the researchers, followed by data analysis. Descriptive statistics, namely frequencies

Figure I: Setup for Photographical Method of Postural Assessment (P-MPA) ${ }^{32}$ 


\begin{tabular}{|c|c|c|c|c|c|c|c|c|}
\hline \multicolumn{9}{|c|}{$\begin{array}{l}\text { Anterior views: } \\
\text { Ask participant if anatomical landmark is left or right of the line plumb line } \\
\text { Lateral views: } \\
\text { Ask participant if anatomical landmark is anterior or posterior of the line plumb line } \\
\text { Ask participant to indicate how much the deviation - } \\
\text { Document findings in the columns below }\end{array}$} \\
\hline VIEW & & SITTING & & & & STAN & DING & \\
\hline ANTERIOR & $\begin{array}{l}\text { DEVIATION } \\
\text { FROM } \\
\text { PLUMB LINE } \\
\text { (participant } \\
\text { indicates) }\end{array}$ & $\begin{array}{l}\text { STICKER TO } \\
\text { THE LEFT } \\
\text { OF PLUMB } \\
\text { LIN Postural } \\
\text { alignment, sense } \\
\text { of posture and } \\
\text { actual posture E - } \\
\text { Tick here }\end{array}$ & $\begin{array}{l}\text { STICKER TO } \\
\text { THE RIGHT } \\
\text { OF PLUMB } \\
\text { LINE - } \\
\text { Tick here }\end{array}$ & $\begin{array}{l}\text { None } \\
\text { Tick here }\end{array}$ & $\begin{array}{l}\text { DEVIATION } \\
\text { FROM } \\
\text { PLUMB LINE } \\
\text { (participant } \\
\text { indicates) }\end{array}$ & $\begin{array}{l}\text { STICKER TO } \\
\text { THE LEFT } \\
\text { OF PLUMB } \\
\text { LINE - } \\
\text { Tick here }\end{array}$ & $\begin{array}{l}\text { STICKER TO } \\
\text { THE RIGHT } \\
\text { OF PLUMB } \\
\text { LINE - } \\
\text { Tick here }\end{array}$ & $\begin{array}{l}\text { None } \\
\text { Tick here }\end{array}$ \\
\hline \multicolumn{9}{|l|}{ Mid heels } \\
\hline \multicolumn{9}{|l|}{ Mid knees } \\
\hline \multicolumn{9}{|l|}{ Navel } \\
\hline \multicolumn{9}{|l|}{ Nose } \\
\hline LATERAL & $\begin{array}{l}\text { DEVIATION } \\
\text { FROM } \\
\text { PLUMB LINE } \\
\text { (participant } \\
\text { indicates) }\end{array}$ & $\begin{array}{l}\text { STICKER } \\
\text { ANTERIOR OF } \\
\text { PLUMB LINE - } \\
\text { Tick here }\end{array}$ & $\begin{array}{l}\text { STICKER } \\
\text { POSTERIOR } \\
\text { OF PLUMB } \\
\text { LINE - } \\
\text { Tick here }\end{array}$ & $\begin{array}{l}\text { None } \\
\text { Tick here }\end{array}$ & $\begin{array}{l}\text { DEVIATION } \\
\text { FROM } \\
\text { PLUMB LINE } \\
\text { (participant } \\
\text { indicates) }\end{array}$ & $\begin{array}{l}\text { STICKER } \\
\text { ANTERIOR } \\
\text { OF PLUMB } \\
\text { LINE - } \\
\\
\text { Tick here }\end{array}$ & $\begin{array}{l}\text { STICKER } \\
\text { POSTERIOR } \\
\text { OF PLUMB } \\
\text { LINE - } \\
\text { Tick here }\end{array}$ & $\begin{array}{l}\text { None } \\
\text { Tick here }\end{array}$ \\
\hline \multicolumn{9}{|l|}{ Lat malleolus } \\
\hline \multicolumn{9}{|l|}{ Mid knee } \\
\hline \multicolumn{9}{|l|}{ Gr trochanter } \\
\hline \multicolumn{9}{|l|}{ Acromion } \\
\hline Ear lobe & & & & & & & & \\
\hline
\end{tabular}

Figure 2: Data capture form

and percentages for categorical data, and medians and percentiles for numerical data, were calculated. The sense of and actual deviation at each landmark, for sitting and standing were compared by means of $95 \%$ confidence intervals $(\mathrm{Cl})$ for median differences for paired data.

\section{Pilot study}

A pilot study was done to clarify any questions participants had regarding the questionnaire or study, and to identify practical obstacles during data collection and the coding of questionnaires. No corrections were made, and results of the pilot study formed part of data analysis.

\section{RESULTS}

Data were collected for 95 participants, from 2 to 13 October 2017 at the sampled clinics. Most participants $(80.0 \%)$ were female with a median age of 42.5 years (range 18.2 to 84.7 years) and a median level of grade 10 education $\{$ range 0 (none) to I 3 (diploma)\}. The majority of participants had a normal weight $(85.3 \%)$ and were of medium length (67.4\%), and $68.4 \%$ of the participants reported to be in good general health.

Results from the biographical questionnaire indicated that more than half $(54.7 \%)$ the participants did not think about their own postural alignment, and more than half $(52.6 \%)$ indicated not being concerned about their own postural alignment. Most (64.2\%) considered themselves as 'in touch with their sense of movement', and $63.2 \%$ considered themselves to be 'in touch with the sense of postural alignment'. Almost all participants $(96.8 \%)$ have never had their posture assessed. The majority of $(73.7 \%)$ participants participated in sport including running $(26.3 \%)$, netball $(54.3 \%)$ and soccer (37.1\%).

Table I (page 4I) depicts all 95 participants' data for sensed and actual (real) postural deviation from the plumb line.

For sense: Participants mostly indicated no deviation from the plumb line for the anterior view, though less indicated no deviation for the lateral view. As can be seen in the range for sense (Table $I$, page $4 I$ ) there were participants who did indicate deviations.

For actual: The pattern of deviation differed from sense as can be seen in Table I, page 4I).

Statistical significant differences were found at all the anatomical landmarks for the lateral view for both sitting and standing between the actual and sensed posture regarding the plumb line. The nose was the only landmark from anterior view that had statistical significant differences between actual and sense per participant, though no clinical significant differences were found at this landmark. Clinical significance was seen as $10 \mathrm{~mm}$ for this study, therefore all the lateral view landmarks, showed clinical significant differences for both standing and sitting.

Table II (page 42) reports on results for participants who sensed a deviation of posture: their sensed and actual deviations are stated.

In order to determine by how much participants' sensed and actual deviations differed, $95 \%$ confidence intervals for the median difference between actual and sense measurements were calculated. A statistical significant difference was indicated in Table II when it occurred (see the footnote at Table II). When sensed deviation oc- 


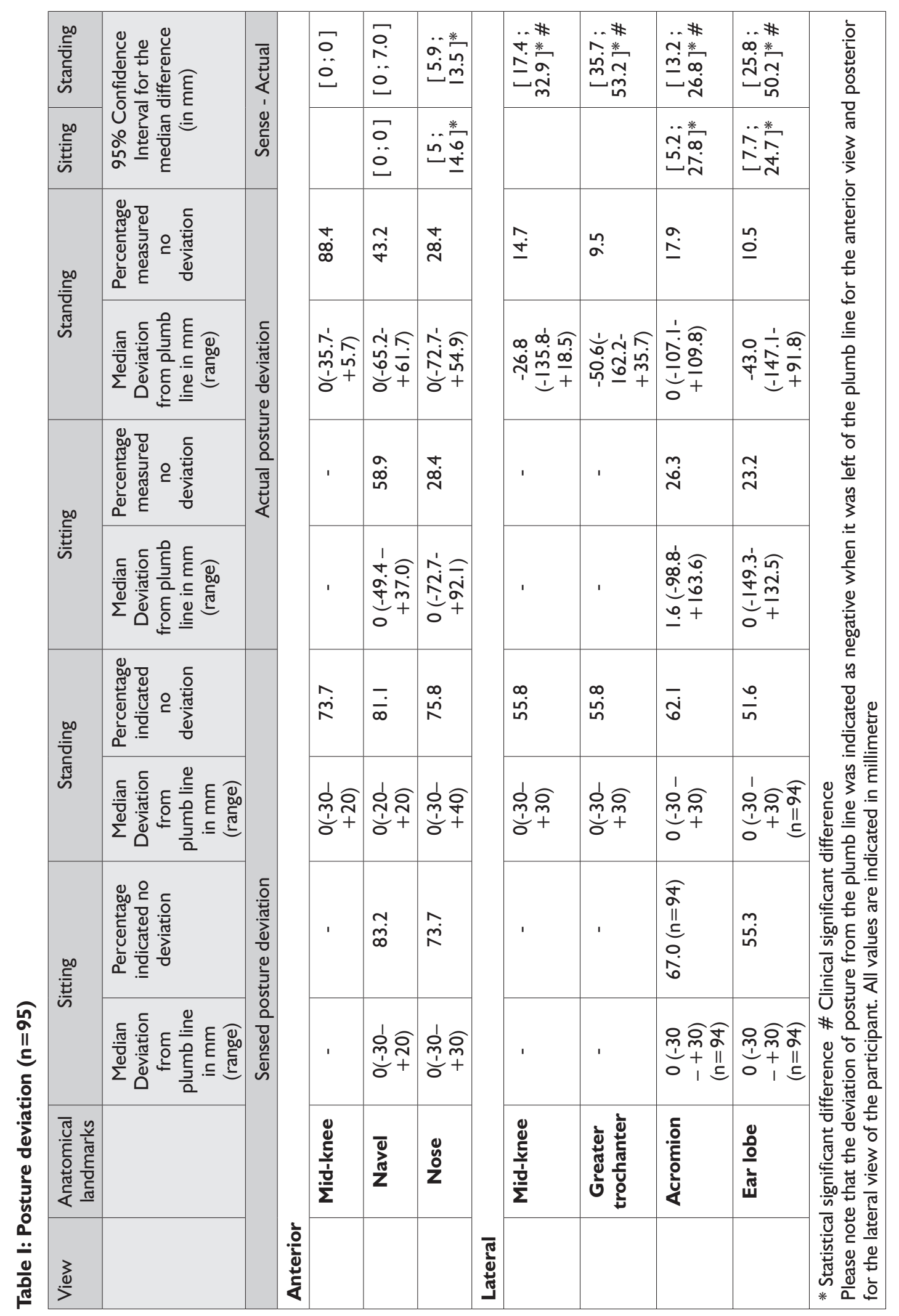


Table II: Sensed and actual deviation for those whom had indicated deviations when sensing posture

\begin{tabular}{|c|c|c|c|c|c|c|c|c|c|}
\hline View & & & Sensed & Actual & & Sensed & Actual & \multicolumn{2}{|c|}{ Sense-Actual } \\
\hline \multirow[t]{5}{*}{ Anterior } & & Frequency & $\begin{array}{c}\text { Median } \\
\text { Deviation } \\
\text { from plumb }\end{array}$ & $\begin{array}{c}\text { Median } \\
\text { Deviation } \\
\text { from plumb }\end{array}$ & Frequency & $\begin{array}{c}\text { Median } \\
\text { Deviation } \\
\text { from plumb }\end{array}$ & $\begin{array}{c}\text { Median } \\
\text { Deviation } \\
\text { from plumb }\end{array}$ & \multicolumn{2}{|c|}{$\begin{array}{l}95 \% \text { Confidence } \\
\text { Interval for the median } \\
\text { difference (in } \mathrm{mm} \text { ) }\end{array}$} \\
\hline & & & \multicolumn{2}{|c|}{ Sitting } & & \multicolumn{2}{|c|}{ Standing } & Sitting & Standing \\
\hline & Mid-knee & & - & - & 25 & $\begin{array}{l}5.0(-30- \\
+20)\end{array}$ & $0(-27.0-0)$ & - & {$[6.1 ; 20]^{*}$} \\
\hline & Navel & 16 & $\begin{array}{l}-7.5(-30- \\
+20) \\
\end{array}$ & $\begin{array}{l}0(-36.4- \\
+35.7) \\
\end{array}$ & 18 & $\begin{array}{l}7.5(-20- \\
+20)\end{array}$ & $\begin{array}{l}0(-14.5- \\
+44.8)\end{array}$ & $\begin{array}{l}{[-8.9 ;} \\
10.0]\end{array}$ & {$[-2.7 ; 10]$} \\
\hline & Nose & 25 & $\begin{array}{c}-5.0(-20- \\
+30)\end{array}$ & $\begin{array}{l}6.0(-72.7- \\
+92.1)\end{array}$ & 23 & $\begin{array}{c}5.0(-30- \\
+40)\end{array}$ & $\begin{array}{l}5.7(-72.7- \\
+50.5)\end{array}$ & $\begin{array}{c}{[-12.2 ;} \\
5.0]\end{array}$ & {$[-14.6 ; 0]$} \\
\hline \multirow[t]{5}{*}{ Lateral } & & & \multicolumn{2}{|c|}{ Sitting } & & \multicolumn{2}{|c|}{ Standing } & & \\
\hline & Mid-knee & & - & - & 42 & $\begin{array}{l}10.0(-30- \\
+30)\end{array}$ & $\begin{array}{c}-31.6(-108.7- \\
+18.5)\end{array}$ & - & $\begin{array}{c}{[-40.6 ;-11.5} \\
]^{*} \#\end{array}$ \\
\hline & $\begin{array}{c}\text { Greater } \\
\text { trochanter }\end{array}$ & & - & - & 42 & $\begin{array}{l}10.0(-30- \\
+30)\end{array}$ & $\begin{array}{c}-56.3(-162.2- \\
0)\end{array}$ & - & $\begin{array}{c}{[-55.2 ;-33.5} \\
]^{*} \#\end{array}$ \\
\hline & Acromion & 32 & $\begin{array}{c}5.0(-30- \\
+30)\end{array}$ & $\begin{array}{l}8.4(-98.8- \\
+163.6)\end{array}$ & 36 & $\begin{array}{c}5.0(-30- \\
+30)\end{array}$ & $\begin{array}{l}-4.4(-95.7- \\
+109.8)\end{array}$ & $\begin{array}{c}{[-21.1 ;} \\
1.8]\end{array}$ & $\begin{array}{c}{[-34.3 ;-14.1} \\
]^{*} \#\end{array}$ \\
\hline & Ear lobe & 43 & $\begin{array}{l}10.0(-30- \\
+30)\end{array}$ & $\begin{array}{c}-11.4(-86.9- \\
+132.5)\end{array}$ & 46 & $\begin{array}{l}10.0(-30- \\
+30)\end{array}$ & $\begin{array}{c}-54.7(-138.3- \\
+91.8)\end{array}$ & $\begin{array}{l}{[-16.5 ;} \\
-0.6]^{*}\end{array}$ & $\begin{array}{c}{[-60.9 ;-28.1} \\
]^{*} \#\end{array}$ \\
\hline
\end{tabular}

Table III: Actual posture deviation measured (only for those who had actual deviations)

\begin{tabular}{|c|c|c|c|c|c|c|c|c|c|}
\hline View & & & Actual & Sensed & & Actual & Sensed & \multicolumn{2}{|c|}{ Sense-Actual } \\
\hline \multirow[t]{5}{*}{ Anterior } & & Frequency & $\begin{array}{l}\text { Median } \\
\text { Deviation } \\
\text { from plumb } \\
\text { line in mm } \\
\text { (range) }\end{array}$ & $\begin{array}{c}\text { Median } \\
\text { Deviation } \\
\text { from plumb } \\
\text { line in mm } \\
\text { (range) }\end{array}$ & Frequency & $\begin{array}{c}\text { Median } \\
\text { Deviation } \\
\text { from plumb } \\
\text { line in } \mathbf{m m} \\
\text { (range) }\end{array}$ & $\begin{array}{c}\text { Median } \\
\text { Deviation } \\
\text { from plumb } \\
\text { line in mm } \\
\text { (range) }\end{array}$ & \multicolumn{2}{|c|}{$\begin{array}{l}95 \% \text { Confidence } \\
\text { Interval for the } \\
\text { median difference (in } \\
\mathrm{mm} \text { ) }\end{array}$} \\
\hline & & & \multicolumn{2}{|c|}{ Sitting } & & \multicolumn{2}{|c|}{ Standing } & Sitting & Standing \\
\hline & Mid-knee & & - & - & 11 & - & $0(-20-+20)$ & - & $\begin{array}{c}{[5.7 ; 30.3} \\
]^{*}\end{array}$ \\
\hline & Navel & 39 & $\begin{array}{c}-5.4(-49.4- \\
+37.0)\end{array}$ & $0(-20-+20)$ & 54 & $\begin{array}{c}{[8.5 ; 13.9} \\
]^{*}\end{array}$ & $0(-10-+20)$ & $\begin{array}{c}{[8.5 ; 13.9} \\
\quad]^{*}\end{array}$ & $\begin{array}{c}{[10.1 ;} \\
14.6]^{*} \#\end{array}$ \\
\hline & Nose & 68 & $\begin{array}{l}\text { I3.3 (-72.7- } \\
\quad+247.3)\end{array}$ & $0(-30-+30)$ & 68 & $\begin{array}{c}{[12.2 ; 21.7} \\
]^{*} \#\end{array}$ & $0(-30-+40)$ & 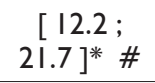 & $\begin{array}{c}{[10.9 ;} \\
18.5]^{*} \#\end{array}$ \\
\hline \multirow[t]{5}{*}{ Lateral } & & & \multicolumn{2}{|c|}{ Sitting } & & \multicolumn{2}{|c|}{ Standing } & Sitting & Standing \\
\hline & Mid-knee & & - & - & 81 & $\begin{array}{c}-34.2 \\
(-135.8- \\
+18.5)\end{array}$ & $0(-30-+30)$ & - & $\begin{array}{c}{[22.7 ;} \\
40.5]^{*} \#\end{array}$ \\
\hline & $\begin{array}{l}\text { Greater } \\
\text { trochanter }\end{array}$ & & - & - & 86 & $\begin{array}{c}-56.3 \\
(-162.2- \\
35.7)\end{array}$ & $0(-30-+30)$ & - & $\begin{array}{l}\text { [37.1; } \\
61.2]^{*} \#\end{array}$ \\
\hline & Acromion & 78 & $\begin{array}{c}-6.7(-107.1- \\
+109.8)\end{array}$ & $0(-30-+30)$ & 36 & $\begin{array}{l}-4.4(-95.7- \\
+109.8)\end{array}$ & $5(-30-+30)$ & $\begin{array}{c}{[15.2 ;} \\
34.1]^{*} \#\end{array}$ & $\begin{array}{c}{[20.3 ;} \\
32.6]^{*} \#\end{array}$ \\
\hline & Ear lobe & 85 & $\begin{array}{c}-45.5(-147.1- \\
\quad+91.8)\end{array}$ & $0(-30-+30)$ & 46 & $\begin{array}{l}-54.7 \\
(-138.3- \\
+91.8)\end{array}$ & $10(-30-30)$ & $\begin{array}{c}{[13.5 ;} \\
30.0]^{*} \#\end{array}$ & $\begin{array}{c}{[33.5 ;} \\
58.2]^{*} \#\end{array}$ \\
\hline
\end{tabular}

curred for mid-knee standing the sensed deviation was significantly more than the actual $(95 \% \mathrm{Cl}[6 . \mathrm{I} ; 20$ ]). For lateral view when deviation was sensed the actual deviation was statistically significant more than the sensed variation $(95 \% \mathrm{Cl}[-40.6 ;-1 \mathrm{I} .5])$. Table III above reports on when actual posture deviation occurred, and the actual and sensed are stated and compared by means of $95 \%$ confidence intervals.

$95 \%$ confidence intervals for the median difference were calculated in order to determine by how much participants' sensed and actual measurements differed. If actual deviation occurred it 
always deviated statistical significantly more than sensed deviation for all landmarks, and with the exception of the navel landmark (anterior view, sitting) and mid-knee (anterior view standing). Sense and actual deviations showed clinically significant differences for all the landmarks.

\section{DISCUSSION}

Good postural alignment provides a basis for effective and safe movement during participation in activities of daily life. The implementation of correct postural alignment in activities of daily life relies largely on accurate sensing of postural alignment and the subsequent repositioning ${ }^{26-29}$ of postural alignment. Literature reports on numerous disciplines' interest in the field of accuracy studies ${ }^{34}$, and results influencing practices and development of professions such as human factors in aviation ${ }^{35}$, sport performance ergonomics and management ${ }^{36}$.

This paper reports on five important findings regarding the accuracy of sensing postural alignment. Firstly, a difference occurs in sensing postural deviation from the plumb line between anterior and lateral views for both the positions of sitting and standing, where participants sensed less deviation from the plumb line in the anterior view than the lateral view. In this regard, the role of vision in the readjustment of posture is well described in literature ${ }^{7,37}$.

In the current study the plumb line fell within the central field of vision of the participant (anterior view). This supports the role of central vision in postural alignment, and consistent with the findings of other investigators, Thomas, Bampouras and Doavan ${ }^{38}$ correspondingly report on increased postural sway during smooth visual pursuits in more challenging stance positions, demonstrating the importance of visual inputs on postural sway of adults during quiet stance. Similarly Agostini et al..$^{39}$ reiterates that central vision seems to affect mostly the medio-lateral direction of postural sway. In further support of the role of vision in perceiving body position, Gibson ${ }^{23}$ found that vision is more dominant than touch and proprioception. Gibson explains if an object was made to merely look large using a lens, while it was being palpated, it also felt large. Findings in literature that also align with results of the present study further report on The Ponzo- and The Mueller-Lyre Illusion ${ }^{40}$ stating that illusions occur when the perceptual processes or perceptual constancy are "altered" by a particular situation so that something is seen that does not exist or that is incorrect. The theory of perceptual constancy suggests that 'we always perceive the same object in the same way, despite the fact that sensations that it creates on our receptors changes dramatically' ${ }^{\prime 2}$. This ability to perceive a stimulus as constant despite changes in visual sensation may further relate to participants in the present study's more accurate interpretation of the plumb line as 'central'.

Secondly, significant differences were observed at all the anatomical landmarks for the lateral view between the actual and sensed posture regarding the plumb line. Regarding the anterior view for the landmark 'nose' (sitting and standing) statistical significant differences were seen between actual and sense per participant, though no clinical significant differences were found.

A third finding from the current study is that, when responses from the participants who sensed deviation from the plumb line (anterior view, standing), were compared to their actual deviation, a statistical significant difference was found at the anatomical landmark of the knee (a weight bearing joint). However, from a lateral view, both statistical and clinical differences were found for all the anatomical landmarks in standing.

Literature on postural adjustment and maintenance indicates the importance of frequency and stretch intensity in sensory fibres, force intensity and joint position ${ }^{41}$, as perceived by receptors throughout the body. The receptors include muscle spindles, Golgi tendon organs and mechanoreceptors ${ }^{42}$. In the current study stability was provided by weight bearing joints i.e. knee and hip joints; whereas the shoulder (acromion landmark) and head (ear lobe) were less exposed to mechanoreceptor proprioceptive input, and more subjected to open kinematic chain movements. Congruent with single joint research findings of King, Harding and Karduna ${ }^{12}$ on accuracy of the knee joint's sensed posture, and Drouin et al's ${ }^{17}$ conclusion that sensed posture is superior in closed kinematic chains ${ }^{43}$, our findings show that statistical as well as clinical significant differences were found for landmarks proximal to the greater trochanter, namely the shoulder (landmark acromion) and ear lobe. These joints are situated more proximally in the kinematic chain and typically perform more open kinematic chain movements. An important finding from the present study, and in contrast with "Feedforward and internal feedback mechanism" "::170,6,11, the weight bearing joints (mid-knee and greater trochanter) also show both statistical and clinical significant differences, indicating that the role of proprioceptive structures' feedback is a clinically noteworthy concern for educational approach to the repositioning of posture. In addition, support for the findings in the current study is further evidenced by Bang et al ${ }^{44}$ who reported that knee proprioception of chronic stroke patients differs significantly between the weightbearing and non-weight-bearing positions.

The fourth finding from the current study indicates that, if actual deviation occurred and the actual deviation from the plumb line was compared with the sensed responses, there were statistical significant differences for all landmarks, and likewise clinical significant differences were found for all landmarks, with the exception of the navel landmark (anterior view, sitting) and mid-knee (anterior view standing). Again, results for the knee joint are in line with proprioception theories relating to weight bearing joints ${ }^{44}$, and similarly to sensed deviation, show no clinically statistical difference between actual and sensed deviations. Although the time aspect was not the focus of the present study, literature indicates that the retention of postural alignment decreases with the passing of time. Xie and Urabe ${ }^{45}$ report a significant increase of the absolute error regarding sensed posture over the time span of 5 to 30 minutes.

A last noteworthy finding from the present study is that all the lateral view landmarks show both statistical and clinical significant differences between sense and actual deviation for standing position.

Congruent with proprioception theories, which argue that perceiving proprioceptive information form part of the individual's 'internal feedback mechanism ${ }^{17,27}$ when trying to adjust and correct postural alignment during activity participation, results from the present study show that the distance(degree) to which a client senses deviation from the plumb line should also be considered and accommodated during assessment and planning of intervention programmes.

\section{RECOMMENDATIONS}

In the absence of existing evidence regarding the accuracy of multijoint postural alignment in sitting and standing, findings from the present study should alert assessment and intervention practices to the discrepancies between sensed and actual postural alignment.

The authors firstly recommend that the distance of deviation from the plumb line be considered an additional aspect in the procedure of assessment and intervention planning to ensure and optimise accuracy in assessment and postural intervention practices.

Secondly, health care professionals and educators are advised to accommodate the discrepancy between sensed and actual postural alignment in the design of educational and intervention programmes. Therefore endeavours to improve on current postural intervention strategies should note the differences between sensed and actual postural alignment, in order to optimise intervention with combined modalities of education and proprioceptive intervention strategies.

Health care professionals practising in the field of postural retraining programmes, should take note that weight bearing joints - functioning in a closed kinematic chain - show a clinically significant difference between sensed and actual repositioning of postural alignment.

The authors recommend that follow up studies investigate postural repositioning during motion and in addition to speed and 
direction, also test the degree to which discrepancy between sense and actual values occurs.

\section{CONCLUSION}

To our knowledge, this is the first study to report on multi-joint postural alignment and the difference between actual and sense deviation from the plumb line. Results from this study showed statistical and clinical significant differences for sense and actual deviations from the plumb line, for certain anatomical landmarks in standing and sitting positions in the anterior and lateral views. The authors therefore wish to raise awareness among health care workers to accommodate for inaccuracy of postural readjustment in the planning of intervention programmes.

\section{ACKNOWLEDGEMENTS}

The researchers acknowledge the contribution of Me N Phatela (occupational therapist, fieldworker), clients and staff of Health Care Clinics in Botshabelo and Thaba N'chu, Dr. M Reid, School of Nursing, UFS, and the Free State Department of Health for sponsoring the project.

\section{REFERENCES}

I. Dolphens M, Cagnie B, Danneels L, De Clercq D, De Bourdeaudhuij I, Cardon G. Long-term effectiveness of a back education programme in elementary schoolchildren: an 8-year follow-up study. European Spine Journal. 20 I I; 20(I2): 2134-42. https://doi.org/I0.1007/s00586-0I I-I856-9

2. Rowe G, Jacobs K. Efficacy of body mechanics education on posture while computing in middle school children. Work. 2002; 18(3): 295303. PMID: $|244| 570$

3. Haibach PS, Reid G, Collier D. Motor Learning and Development. New York: Human Kinetics, 201 I.

4. Rohlman A, Pohl D, Bender A, Graichen F, Dymke J, Schmidt H, Gergman G. Activities of Everyday Life with High Spinal Loads. PLoS ONE. 20I4; 9(5): e985I0.

https://doi.org/I0.137I/journal.pone.00985I0

5. Inoue N, Orias AAE. Biomechanics of the Intervertebral disc Degeneration. Orthopedic Clinics. 20I I, 42(4): 487-499. https://doi.org//0.1016/j.ocl.2011.07.001

6. Simpson TT, Wiesner SL, Bennet BC. Dance Recognition System Using Lower Body Movement. Journal of Applied Biomechanics. 2014; 30(I): 147-153.

https://doi.org//0.1 I 23/jab.2012-0248

7. Shumway-Cook A, Woollacott M. Motor control: translating research into clinical practice. 4th ed. Baltimore: Lippincott Williams \& Williams, 2012.

8. Posture Committee of the American Academy of Orthopaedic Surgeons. Posture and its relationship to orthopaedic disabilities: A report of the Posture Committee of the American Academy of Orthopaedic Surgeons. Evanston, III: American Academy of Orthopaedic Surgeons; 1947: I.

9. Kendall FP McCreary EK, Provance PG. Muscle testing and function with posture and pain. $5^{\text {th }}$ ed. Baltimore: Lippincott, Williams \& Wilkins, 2005.

10. Brunnstrom, Smith L, Weiss EL, Lehmkuhl LD. Brunnstrom's Clinical Kinesiology. $5^{\text {th }}$ Edition. Philadelphia: F.A. Davis Company, 1996.

II. Longo MR, Haggard P. An implicit body representation underlying human position sense. Proc Natl Acad Sci U S A. 2010; 107(26): I I 727-32. https://doi.org//0.1073/pnas. 1003483107

12. King J, Harding E, Karduna A. The Shoulder and Elbow Joints and Right and Left Sides. Journal of Motor Behavior. 20 I 3; 45(6):479-486. https://doi.org// 0.1080/00222895.2013.832I 36

13. Jang IY, Kang DH, Jeon JK, Jun HJ, Lee JH. The effects of shoe heel height and gait velocity on position sense of the knee joint and balance. Journal of physical therapy science. 2016; 28(9): 2482-2485. https://doi.org// 0.1589/jpts.28.2482

14. King J, Harding E, Karduna A. The Shoulder and Elbow Joints and Right and Left Sides. Journal of Motor Behavior. 2016; 45: 479-486. Epub, 20I3; Sep 30. https://doi.org/10.1080/00222895.2013.832136
I5. Olsson L, Lund H, Henriksen M, Røgind H, Bliddal H, DanneskioldSamoe B. 2004. Test-/retest Reliability of a Knee Joint Position Sense Measurement Methods in Sitting and Prone Position. Advances in Physiotherapy. Volume 6: 37-47. https://doi.org//0.1080//4038190310009894.

16. Herrington L. Knee-Joint Position Sense: The Relationship Between Open and Closed Kinetic Chain Tests. Journal of Sport Rehabilitation. 2005; I4(4): 356-62. https://doi.org/10. I | 23/jsr. I4.4.356

17. Drouin J, Houglum P, Perrin D, Gansneder B. Weight-bearing and non-weight bearing knee-joint reposition sense and functional performance. Journal of Sport Rehabilitation. 2003; I2(I):54-66. https://doi.org/I0.1 I 23/jsr.6.4.327

18. Magalhães T, Ribeiro F, Pinheiro A, Oliveira J. Warming-up before sporting activity improves knee position sense. Physical Therapy in Sport. 20I0; II (3):86-90. https://doi.org/I0.1016/j.ptsp.2010.06.00I

19. Bouët $\mathrm{V}, \mathrm{Gahéry} Y$. Muscular exercise improves knee position sense in humans. Neuroscience Letters. 2000; 289(2): I43-I 46. https://doi.org/I0.1016/S0304-3940(00)01297-0

20. Shang-Lin Chiang, Liang-Hsuan Lu, Shun-Hwa Wei, and Wen-Hsu Sung. Validity of an ankle joint motion and position sense measurement system and its application in healthy subjects and patients with ankle sprain. Computer Methods and Programs in Biomedicine. 2016; 131:89-96. https://doi.org/10.1016/j.cmpb.2016.03.026

2I Chueh-Ho Lin, Shang-Lin, Shun-Hwa Wei, Wen-Hsu Sung. 2016. Validity of an ankle joint motion and position sense measurement system and its application in healthy subjects and patients with ankle sprain. Computer Methods and Programs in Biomedicine. Volume |31: 89-96. https://doi.org/10.1016/j.cmpb.2016.03.026

22 Brindle, T.J. Mizelle JC, Lebiedowska MK, Miller JL, Stanhope SJ. 2009. Visual and proprioceptive feedback improves knee joint position sense. Knee surg Sports Traumatol Arthrosc. I7(I): 40-7. Epub 2008 Oct 7. https://doi.org/10.1007/s00 I67-008-0638-3.

23. Gibson JJ. Observations on active touch. Psych Rev. 1962; 69(6): 477-91. https://doi.org//0.1037/h0046962

24 Unpublished research findings: Nel M, Yang, Y, Miles Z, Kritzinger J, Laubscher M, Nel C, Klopper L, Hough P. Sense of alignment compared to actual alignment of posture. 2018. Department of Occupational Therapy, University of the Free State.

25. Proske $U$ and Gandevia SC. The proprioceptive senses: their roles in signalling body shape, body position and movement, and muscle force. Physiol Rev. 2012; 92: I65I-1697. https://doi.org/I0.I I 52/physrev.00048.20 I I

26. Saunders I, Vijayakumar S. The role of feed-forward and feedback processes for closed-loop prosthesis control. J Neuroeng Rehabilitation. 20II; 8: 60. https://doi.org/I0.I I86/1743-0003-8-60

27. Ayres A. Sensory Integration and the Child. 25th Anniversary Edition. Los Angeles: WPS Publishers, 2010.

28. Pearson KG. Proprioceptive regulation of locomotion. Curr Opin Neurobiol. 1995; 5:786-79I. https://doi.org/10.1016/0959-4388(95)80107-3

29. Enoka RM. Neuromechanics of Movement. 5th edition. 2015. Champaign: Human Kinetics Publishers.

30. Hartsell HD. The effects of external bracing on joint position sense awareness for the chronically unstable ankle. Journal of sport rehabilitation. 2000; 9(4): 279-289.

https://doi.org/I 0. I I 23/jsr.9.4.279

31. Boisgontier, M.P, Nougier V. Proprioception: bilateral inputs first. Neuroscience letters. 20I3; 534-96-I00. https://doi.org/I0.1016/j.neulet.2012.11.050

32. Hough PA, Nel M. Part I: Validity and reliability of a Photographic Method for Postural Assessment (P-MPA). South African Journal of Occupational Therapy. 2019; 49(2): 42-47 DOI: http://dx.doi.org/10.17159/2310-3833/2017/vol49n2a7

33. Grosso C, Negrini S, Boniolo A, Negrini A. The validity of the clinical examination in adolescent spinal deformities. Studies in Health Technology Informatics. 2002; 91: I23-5. https://doi.org/I0.3233/978-I-60750-935-6-123 
34. Holmes SR, Bunting A, Brown DL, Hiatt KL, Braithwaite MG, Harrigan MJ. Survey of spatial disorientation in military pilots and navigators. Aviation Space Environmental Medicine. 2003; 74(9): 957-65.

35. Chia-Chien Wu, Oh-Sang Kwon, Eileen Kowler. Fitts's Law and speed/accuracy trade-offs during sequences of saccades: Implications for strategies of saccadic planning. Vision Res. 2010 Oct I2; 50(2I): 2142-2157.

https://doi.org/10.1016/j.visres.2010.08.008

36. C.Viviania PM, Arezesb S, Bragançac J, Molenbroek I, Dianate HI, Castellucci. Accuracy, precision and reliability in anthropometric surveys for ergonomics purposes in adult working populations: A literature review. International Journal of Industrial Ergonomics. 2018; 65:I-16.

https://doi.org/10.1016/j.ergon.2018.01.012

37. Palliard J. Cognitive versus sensorimotor encoding of spatial information. In: Ellen P, Thinus-Blanc C, eds. Cognitive processes and spatial orientation in animal and man: neurophysiology and developmental aspects. The Hague: Martinus Nijhoff, 1987.

38. Thomas NM, Bampouras TM. Donovan T, Dewhurst S. Eye Movements Affect Postural Control in Young and Older Females. Frontiers in Aging Neuroscience. 2016; 8: 216. https://doi.org/I0.3389/fnagi.2016.00216

39. Agostini V, Sbrollini A, Cavallini C, Busso A, Pignata G, Knaflitz M. The role of central vision in posture: Postural sway adaptations in Stargardt patients. Gait Posture. 2016; 43: 233-8. https://doi.org/10.1016/j.gaitpost.2015.10.003

40. Accuracy and inaccuracy in perception, in Introduction to Psychology. University of Minnesota Libraries Publishing. 2010. https://open.lib.umn.edu/intropsyc/chapter/4-5-accuracy-andinaccuracy-in-perception/

4I. Elangovan, N. Proprioceptive training and Motor Transfer in Patients with Parkinson's Disease. A Dissertation submitted to the faculty of University of Minnesota, Minnesota: University of Minnesota, 2016. http://hdl.handle.net/I I 299//85 I83

42. Fox SI. Human Physiology. I $3^{\text {th }}$ Ed. New York: McGraw-Hill, 2013.

43. Andersen SB, Terwilliger DM, Denegar CR. Comparison of open versus closed kinetic chain test positions for measuring joint position sense, Journal of Sport Rehabilitation, 1995; 4(3): I65-7I. https://doi.org//0.3389/fneur.2018.01053

44. Bang DH, Shin WS, Choi SJ, and Choi HS. Comparison of the effect of weight-bearing and non-weight-bearing positions on knee position sense in patients with chronic stroke. J Phys Ther Sci. 20I5; 27(4): I203-1206. https://doi.org//0.1589/jpts.27.1203

45. Xie D, Urabe Y. 20I4. How Long Can Joint Position Sense Be Retained in Memory by Young Healthy Subjects. Journal of Physical Therapy Science. 2014; 26(I):33-35.

https://doi.org//0.1589/jpts.26.33

\section{AUTHORS ROLES}

- PA Hough conceived the idea for the research, and gave input regarding the development of the protocol, analysis, and writing of this article.

- M Nel gave input during the development of the protocol, did the analysis, and gave input during the writing of the article.

\section{Corresponding Author}

\section{PA Hough}

Email: HoughPA@ufs.ac.za 